\title{
Adverse drug reactions caused by drug-drug interactions in cardiovascular disease patients: introduction of a simple prediction tool using electronic screening database items
}

Milena Kovačević, Sandra Vezmar Kovačević, Slavica Radovanović, Predrag Stevanović \& Branislava Miljković

To cite this article: Milena Kovačević, Sandra Vezmar Kovačević, Slavica Radovanović, Predrag Stevanović \& Branislava Miljković (2019): Adverse drug reactions caused by drugdrug interactions in cardiovascular disease patients: introduction of a simple prediction tool using electronic screening database items, Current Medical Research and Opinion, DOI: 10.1080/03007995.2019.1647021

To link to this article: https://doi.org/10.1080/03007995.2019.1647021

Accepted author version posted online: 22 Jul 2019.

Submit your article to this journal ¿

Џlll Article views: 19

View Crossmark data ¿ 


\title{
Adverse drug reactions caused by drug-drug interactions in cardiovascular disease patients: introduction of a simple prediction tool using electronic screening database items
}

\author{
Milena Kovačević ${ }^{\mathrm{a} \text {, }}$ Sandra Vezmar Kovačević a , Slavica Radovanović ${ }^{\mathrm{b}, 1}$, \\ Predrag Stevanović ${ }^{\text {b, } 1}$, Branislava Miljković ${ }^{\text {a }}$
}

a Department of Pharmacokinetics and Clinical Pharmacy, University of Belgrade, Faculty of Pharmacy, Vojvode Stepe 450, 11000 Belgrade, Serbia

b University Clinical Hospital Center Bezanijska Kosa, University of Belgrade - Faculty of Medicine, Belgrade, Serbia, Bezanijska Kosa bb, 11080 Belgrade, Serbia

*Corresponding author

Milena Kovačević

Faculty of Pharmacy, University of Belgrade, Belgrade, Serbia

Department of Pharmacokinetics and Clinical Pharmacy

Vojvode Stepe 450, 11000, Belgrade, Serbia

e-mail: milenak@pharmacy.bg.ac.rs

Tel: +381 113951373

Fax: +381113972 840

https://orcid.org/0000-0003-2957-7965

1 Present address: University Clinical Hospital Center Dr Dragisa Misovic-Dedinje, University of Belgrade - Faculty of Medicine, Heroja Milana Tepica 1, 11000 Belgrade, Serbia 


\section{Adverse drug reactions caused by drug-drug interactions in cardiovascular disease patients: introduction of a simple prediction tool using electronic screening database items}

Objective: Cardiovascular disease (CVD) drugs have been frequently implicated in adverse drug reaction (ADR)-related hospitalisations. Drug-drug interactions (DDIs) are common preventable cause of ADRs, but the impact of DDIs in the CVD population has not been investigated. Hence, the primary aim of the study was to identify DDIs associated with ADRs in CVD patients at hospital admission. The second aim was to develop a simple tool to identify high-risk patients for DDI-related adverse event.

Methods: An observational study was conducted on Cardiology ward of University Clinical Hospital Center. Data were obtained from medical charts. A clinical panel identified DDIs implicated in ADRs, using LexiInteract database and Drug Interaction Probability Score. Statistics were performed using PASW 22 (SPSS Inc.)

Results: DDIs contributed to hospital admission with a total prevalence of 9.69\%. DDIrelated ADRs affected mainly cardiac function (heart rate or thythm, 41.07\%); bleeding and effect on blood pressure were equally distributed (17.86\%). Non-cardiovascular ADRs were found in $23.21 \%$ of DDIs. After the admission, $73 \%$ of the identified DDIs led to changes in prescription. Prediction ability of calculated DDI-adverse event probability scores was rated as good $(\mathrm{AUC}=0.80, \mathrm{p}<0.001)$.

Conclusions: CVD patients are highly exposed to adverse DDIs; about one in ten patients hospitalized with CVD might have a DDI contributing to the hospitalisation. Given the high prevalence of CVD, DDI-related harm might be significant burden worldwide. Identification of patients with high DDI-adverse event risk might ease the recognition of DDI-related harm and improve the use of electronic databases in clinical practice.

Keywords: drug-related side effects and adverse reactions; drug interactions; patient safety; hospitalization 


\section{Introduction}

Drug safety has become a public health issue, earning significant and wide interest at all levels of health care. ${ }^{1}$ The benefit-risk ratio of a particular drug has become more complex to assess and interpret, due to an increased number of drugs in therapy in the ageing population, and the volume of knowledge about drug-drug and drug-disease interactions. ${ }^{2}$ Besides its challenging aspect in achieving effective and safe therapy for an individual patient, drug-related harm substantially contribute to health care costs. ${ }^{3,4}$ An adverse drug reaction (ADR) is defined as "any response to a drug which is noxious and unintended, and which occurs at doses normally used in man for prophylaxis, diagnosis, or therapy of disease, or for the modification of physiological function". 5 ADRs can occur in appropriately prescribed, dispensed or administered drugs (considered as nonpreventable), but they can also be caused by drug-drug interactions (DDIs) when an altered drug effect emerge in a presence of the precipitant drug. DDIs are identified as a preventable cause of ADRs, irrespective of the study setting. ${ }^{6,7}$ DDIs accounted for $16.6-49 \%$ of ADR-related hospitalisations ${ }^{7-10}$, and were present in about $44 \%$ of cases reported as drug-related deaths in a university hospital. ${ }^{11}$ Epidemiological data derived from meta-analysis estimated the total median prevalence rate of DDI-related hospital admissions to about $1.1 \% .{ }^{7}$ However, it was reported that the low incidence of DDIs might be an indication of a lack of understanding and recognition of DDIs. ${ }^{12}$ Other authors also stated that the true extent of DDI-related harm is not well established. ${ }^{13,14}$ Nevertheless, both researchers and health professionals agree upon the need for generating new evidence on DDIs, to reach improvements in drug safety. ${ }^{15,16}$

Drugs used for cardiovascular disease (CVD) lead the list of ADRs and DDIs causative agents, identified both through a detailed medical charts exploration in epidemiological research, as well as through spontaneous reporting. A comprehensive review by Al Hamid et al. reported that |each and every study| assessing hospitalisation resulting from ADRs, reported CVD medicines, 
with a median of $33.9 \%$ (interquartile range 19.9-58.6\%). ${ }^{17}$ Furthermore, a large French study on more than 6.9 million outpatient dispensings revealed dominant involvement of CVD drugs in DDIs: four out of five most represented contraindicated drug pairs, and all of the five most represented discommended drug pairs involved cardiovascular drugs. ${ }^{18}$ In addition, patients with CVD are at higher risk and exposure to DDIs because of the multiple medications, as well as the administration of drugs with narrow therapeutic index, such as warfarin or digoxin. ${ }^{1,19}$ Prescribing of several drugs is common in CVD, which is the main reason for the reported high prevalence of potential DDIs: $91.1-93.7 \%$ of hospitalised cardiac patients had at least one potential clinically significant DDI regardless of the type of severity. ${ }^{20,21}$ The DDI-related harm in general, as well as their impact on hospital admissions in the population of CVD patients has not been well examined. Studies carried out in CVD patients investigated iatrogenic adverse events emerging during hospitalization in the coronary care unit, assessing both those resulting from medical procedures and the medication use. ${ }^{22,23}$ Others provided general prevalence rates of drug-related problems in CVD patients during hospital stay ${ }^{24}$, or DDIs were assessed only in the cohort of heart failure patients. ${ }^{25,26}$ Another issue in assessing DDIs impact is the causality assessment. The only available tool so far is a 10-item Drug Interaction Probability Scale (DIPS), proposed by Horn and colleagues. ${ }^{27}$ The DIPS purpose is to ease the judgement of the contributory role of a potentialDDI to a specific patient outcome, in comparison to other potential causes. Electronic databases can be easily applied in DDIs screening, giving the opportunity to quickly assess potential problems in patients therapy. However, significant override rates have been reported for DDIs alerts (up to $72.8 \%$ ), due to alert fatigue caused by a high frequency of generated alerts in computerized physician order systems, or intended prescriptions. ${ }^{28}$ Therefore, the primary aim of the study was to identify DDI-related ADRs, suspected to cause or contribute to the clinical findings obtained at the moment of hospital admission in CVD patients. The second aim was to develop a simple prediction tool based on existing LexiInteract ${ }^{\circledR}$ monograph items ${ }^{29}$, to identify patients having high cumulative risk for 
the occurrence of an adverse event due to DDI.

\section{Methods}

Study design and setting

An analytical observational study was conducted investigating consecutive patient admissions on Cardiology ward of University Clinical Hospital Center Bežanijska Kosa, Belgrade, Serbia. University Center is a state-owned, non-profit, general hospital with 400 beds. It is located in the capital of Serbia, providing care to the patients from Belgrade as well as to more complex patients from the other parts of Serbia, who needed more specific diagnostic or interventional procedures. Cardiology ward is a department of Internal medicine Clinic, which receives adults with acute and chronic cardiovascular disorders for admission as well as for outpatient examination and treatment. The Ethics committee of the University Clinical Hospital Center Bežanijska Kosa approved this study (No 222/3).

\section{Patient data}

Patients demographic and clinical data were obtained from medical charts. All patients having complete data, including demographic data such as age and gender, medical history, reason for hospitalisation, clinical and laboratory parameters noted at the admission, as well as the therapy used before and during hospitalisation were included in the study. Additionally, in case of noted physician suspicion on the adherence, those patients were excluded from the study. We collected data on complete therapy used in the outpatient setting prior to admission to hospital (including medications, supplements, and OTC products), which were used at least a month before the admission. An exact time of introduction in therapy was noted for antiinfective agents. 


\section{Identification of potential DDIs}

Screening for potential DDIs was performed using LexiInteract electronic database (Lexi-Comp, Inc., Hudson, Ohio). ${ }^{29}$ Risk rating classes X, D, and C were considered as potential clinically significant DDIs (risk rating scale presented in Table 1). Additionally, LexiInteract monograph was used to extract data on proposed mechanism, severity and reliability of a DDI. Severity indicators include: minor (effects would be considered tolerable in most cases - no need for medical intervention); moderate (medical intervention needed to treat effects; effects do not meet criteria for major); and major (effects may result in death, hospitalization, permanent injury, or therapeutic failure). LexiInteract gives a brief presentation of published data referring to the observed/presumed interaction in the Discussion section of DDI monograph, with medical literature citations. Depending on the type and quality of published evidence for a certain DDI, reliability was defined as poor, fair, good, or excellent.

\section{Table 1}

\section{Identification of ADRs associated with DDIs}

In the next step, a clinical panel consisted of a cardiologist (22 years clinical experience as a specialist in internal medicine, 8 years clinical experience as a subspecialist in cardiology), a clinical pharmacist (7 years clinical experience, with 2 years on cardiology ward), and a PhD student in clinical pharmacy (1 year experience on cardiology ward) reviewed the patients medical charts. Data on clinical findings reported at the admission were thoroughly discussed, estimating the impact of potential DDIs on patients clinical and laboratory parameters. Causality between the adverse event and the suspected DDI were assessed using Drug Interaction Probability Scale (DIPS) introduced by Horn et al. The Naranjo scale, which estimates the probability that an ADR was caused by a single drug, was used as a basis for the DIPS. ${ }^{27}$ The application of the DIPS to a potential DDI requires knowledge of the pharmacologic, pharmacokinetic and pharmacodynamic properties of the object and precipitant drug. DIPS uses 
a series of 10 questions to assess the probability that a causal relationship exists between an event observed in a patient and the coadministration of two drugs. The scale comprises the evaluation of DDI in terms of: (1) previous credible reports; consistency with the known properties of (2) precipitant or (3) object drug; (4) time course; (5) dechallenge; (6) rechallenge; (7) alternative causes; (8) concentration of object drug in blood or other fluids; (9) other objective evidence, other than drug concentration; (10) change in the interaction with precipitant drug dose change. Each question is answered with a "yes," "no," or "unknown/not applicable" response, with assigned numeric score for each question. The total score is used to estimate the probability that the interaction is causally related to the patient event. In our study, potential DDIs with the estimated at least probable causality (DIPS score $\geq 2$ ) with the adverse event reported in the medical charts, and upon the agreement of all the panelists, were coded as adverse DDIs.

\section{Statistical analysis}

Descriptive and inferential statistics were performed using PASW 22 (SPSS Inc., Chicago, IL, USA). Categorical variables were reported as the number of patients with percentage, ordinal as the median value with interquartile and total range, and continuous as the mean value \pm standard deviation with total range. Chi-square (or Fisher's exact test, where appropriate) and Mann Whitney tests were used to assess the difference in patients characteristics between groups with and without DDI-related ADR. Binary logistic regression was used to investigate the factors associated with the occurrence of DDIs involved in ADRs. Odds ratios, both crude and adjusted for the number of drugs, were reported. A two-tailed $\mathrm{p}$ value $<0.05$ was considered statistically significant. Estimated odds ratios were further used as the scoring points in calculating the DDIadverse event (DDI-AE) probability score. DDI-AE score is based on LexiInteract monographs, which reference to published studies on DDIs (in vitro, animal or human studies, where available), or rely on data given in the summary of products characteristics. Even though a 
certain extent of drug-adverse effect relationship might be suspected from the LexiInteract monograph, a causality in an individual patient is assumed to be assessed after the calculation of DDI-AE score, i.e. only in patients with calculated high cumulative risk of DDI manifestation. Therefore the score was named for the term ,event“. Diagnostic accuracy of the DDI-AE probability score was tested using receiver operating characteristic (ROC) analyses. Performance was defined as acceptable when $\mathrm{AUC}=0.70-0.79$, excellent when $\mathrm{AUC}=0.80-0.89$, and AUC $\geq 0.9$ is considered outstanding. ${ }^{30}$ 


\section{Results}

A total of 421 consecutive medical records were retrieved, where 54 patients $(12.8 \%)$ had incomplete data on therapy used before the admission, and 16 patients $(3.8 \%)$ were marked as non-adherent, according to open-form notes made by the accountable physician at the admission. Finally, a total of 2089 drug prescriptions were found in 351 patients at the moment of admission. The median number of drugs per patient was 6 (interquartile range 4-8, total range 115). Polypharmacy ( $\geq 5$ drugs) was present in $68.95 \%$ and $\geq 10$ drugs were found in $8.83 \%$ of patients. Patients were mainly older (aged $\geq 65$ years; $254,72.36 \%$ ), and $48.43 \%$ (170) were females. Table 2 presents the demographic and clinical characteristics of the study population.

\section{Table 2}

\section{Potential DDIs}

Given the number of drugs, a total of 5908 drug pairs were tested for potential DDIs. Potential clinically significant DDIs (X, D and C class) were identified in 1606 drug pairs (27.18\%). The vast majority of drug pairs were in C class (1452, 90.41\%), 143 (8.90\%) DDIs were in D class, and only $11(0.68 \%)$ were in X class, accordingly to risk rating. The total prevalence of potential clinically significant DDIs was estimated to $83.19 \%$ (292 patients).

\section{Adverse drug reactions associated with DDIs}

The clinical panel identified a total of 56 drug pairs being suspected to cause or contribute to clinical findings obtained at the moment of hospital admission. According to LexiInteract, those adverse interacting drug pairs actually corresponded to 30 unique DDIs implicated in ADRs. ADRs attributed to DDIs were identified in 34 patients, with a total prevalence of $9.69 \%$ in the studied population. In patients having at least one potential DDI at admission, the prevalence of ADRs attributed to DDIs was calculated to $11.64 \%$. Most frequent 
adverse DDIs were C class (40 DDIs, 71.43\%), followed by D class (14 DDIs,25\%), and only 2 DDIs (3.57\%) were assigned an X class risk rating. Severity, as graded by LexiInteract was assessed as moderate in 35 DDIs (62.5\%), and major in 21 DDIs (37.5\%). Regarding DDI reliability stated in the LexiInteract monograph, there were only 7 DDIs (12.5\%) reported as excellent, $12(21.43 \%)$ reported as good, and 37 (66.07\%) reported as fair based on the published reports. In total, 41 different drugs (INN) from seven ATC classes were involved in actual DDI-related ADRs. The highest frequency was observed for cardiovascular system drugs (ATC class C, 46 out of 112), with mainly involved ACE inhibitors (10 times). Table 3 shows the frequency of ATC classes with class members implicated in DDI-related ADRs.

\section{Table 3}

Detailed data on identified ADRs attributed to DDIs are given in Table 4. ADRs most frequently involved effect on cardiac function (41.07\%) -tachycardia or irregular heart rhythm $(\mathrm{N}=20,35.7 \%)$, and much less frequent bradycardia $(\mathrm{N}=3,5.36 \%)$. Bleeding and effect on blood pressure were equally distributed $(\mathrm{N}=10,17.86 \%)$, whereas hypotension was more frequent, than hypertension. Non-cardiovascular events were found in $23.21 \%$ of cases, including hyperkalemia, low red cell count, elevated liver enzymes, epigastric pain, and hyperthermia. After the admission, 14 (25\%) DDIs remained during the hospitalisation without dose adjustments of either object or precipitant drug, in one case (2\%) the dose of object drug was decreased, and 41 (73\%) of identified DDIs led to changes in prescription.

\section{Table 4}

\section{Calculation of DDI-AE probability score}

Among patients characteristics, the prevalence of adverse DDIs was not associated with gender or older age (Table 5). Statistical significance was shown only for the number of drugs, with the odds ratio estimated to 1.42 (95\% CI 1.23-1.63), $\mathrm{p}<0.001$. Characteristics of potential 
DDIs, such as risk rating class, severity and the underlying DDI mechanism, were significantly associated with the adverse outcome of DDIs in the studied population (Table 5). Odds ratios presented in Table 5, were used to calculate the DDI-AE probability score. Items with the proposed points are presented in Table 6. Two DDI-AE probability scores were tested, DDI-AE 1 including only DDIs features, and DDI-AE 2 including both DDIs features and the number of drugs.

\section{Table 5}

Table 6

Prediction ability of DDI-AE probability score

Performance of DDI-AE probability scores was rated as good, with the results comparatively presented in Table 7. DDI-AE 1 score differed significantly between patients with and without DDI-related ADR at admission: median 9.00 [IQR 7.75-11], and 6 [IQR 0-7] $(\mathrm{p}<0.001)$, respectively. Median values for DDI-AE 2 score were 21.60 [IQR 15.80-23.70] in patients with DDI-related ADR, compared to 13 [IQR 5.60-18.20] $(\mathrm{p}<0.001)$ in patients without adverse DDI implicated in admission. ROC analyses to evaluate the diagnostic accuracy of DDIAE 1 and DDI-AE 2 probability score yielded an AUC of 0.800 (95\% CI 0.744-0.856) and 0.811 (0.750-0.872), respectively. In spite of slightly lower AUC value, DDI-AE 1 score (not including the number of drugs in the score estimation) showed somewhat better sensitivity and specificity features. The suggested cut-off of 7 points for DDI-AE score 1 demonstrated $76.5 \%$ sensitivity and $77.9 \%$ specificity in predicting the occurrence of adverse drug event given the characteristics for potential DDIs stated in the LexiInteract monograph.

\section{Table 7}




\section{Discussion}

To our knowledge, the prevalence of DDI-related hospitalisations and the identification of adverse DDIs have not been previously investigated in CVD patients. Our study revealed the prevalence of DDI-related ADRs in $9.69 \%$ of CVD admissions to the cardiology service of our hospital. ADRs related to DDIs were uncommon and usually not major, but it is likely that in non-academic hospitals and non-specialty services the frequency may be substantially higher. In our study, adverse DDIs mainly affected cardiac function (41.07\%) - causing tachycardia or irregular heart rhythm (35.7\%), and much less frequent bradycardia (5.36\%). Bleeding and effect on blood pressure were equally distributed (17.86\%), whereas non-cardiovascular events were found in $23.21 \%$ of adverse DDIs. Gastrointestinal tract bleeding (33-40\%), hyper- and hypotension (18\%), and cardiac rhythm disturbances (18-30\%) were identified to be the most frequent adverse events resulting from DDIs. ${ }^{7,12}$ The study setting might hold the explanation for the discrepancy in gastrointestinal tract bleeding frequency, as those patients might be more frequently admitted through emergency department or hospitalised at gastroenterology ward.

Interestingly, the proportion of patients with liver or renal disease in anamnesis was significantly lower in the group with adverse DDI (Table 2). It might reflect the increased and existing awareness on drugs prescribing in patients with known decrease in liver or renal function, as a well known risk of ADRs occurrence. Still, harmful drug combinations have been identified in about $10 \%$ of CVD patients. Nevertheless, a higher prevalence of adverse DDIs might be expected in CVD patients, due to interacting potential of CVD drugs. ${ }^{1}$ Additionally, it was reported CVD itself might increase the risk of ADRs, by altering renal and hepatic perfusion, or causing hypoxia. ${ }^{31}$ Hence, drug elimination and tolerability may be further compromised in CVD patients, irrespective of other risk factors. ${ }^{31,32}$ Other studies dealing with cardiac inpatients reported ADR occurrence in $34 \%$ of patients during hospital stay ${ }^{33}$, whereas the incidence of clinically important DDIs in cardiology department was reported to about 
$15 \% .{ }^{34}$ Further, the wide variety of non-CVD drugs involved in DDIs were identified in our study, which assert the benefit of using DDI screening tools. Cardiologists are certainly well trained for CVD drugs and the expected effect of their concomitant use. However, drugs used in other therapeutic areas such as neurology, mental disease, respiratory disease, and urogenital disease, may have quite specific pharmacokinetic and pharmacodynamic and PD characteristics, which certainly require an electronic base support in assessing drugs interacting potential. It was confirmed that potential DDIs arise more often as a result of prescriptions from multiple prescribers than from a single caregiver prescribing multiple drugs. ${ }^{35}$

Previous studies underlined that DDIs represent a real problem in clinical practice. ${ }^{6}$ The main strategy for reducing DDIs is to use electronic decision support tools, which usually present DDIs as interruptive alerts. ${ }^{36}$ Inevitably, alert fatigue and high rates of alert override are well-recognized consequences of receiving a high volume of DDI alerts. The issues of electronic alert fatigue and override rates were briefly described in the literature ${ }^{28,37}$, carrying the risk that prescribers may miss warnings of potentially serious adverse events. ${ }^{36}$ The most frequently proposed strategy to combat alert fatigue is to reduce the total number of DDI alerts, by elimination of minor and/or moderate DDIs. ${ }^{36,38,39}$ However, our study demonstrated that the majority of adverse DDIs were classified as $\mathrm{C}$ class (about 71\%), attributed the lowest risk rating among all potential clinically significant DDIs, which is highly expected to be neglected in most of the DDI alerts. In addition, severity was graded as moderate in $62.5 \%$ and $37.5 \%$ of adverse DDIs. Given the high prevalence of potential clinically significant DDIs with 83\%, other strategies have to be employed to deal with the alert fatigue in CVD patient population. We aimed to develop DDI-AE probability score to decrease the possibility for alert overrides through presenting a cumulative risk of DDIs, "displaying" only high-risk patients during the electronic prescribing process. The items used in calculating DDI-AE probability score are 
already incorporated in the LexiInteract monograph. Thus, the proposed score could be easily calculated as an add-on feature in the LexiInteract database. Although the number of drugs have been independent risk indicator for adverse DDI occurrence, better results were obtained for DDI-AE 1 score (cut-off value $\geq 7$ points). Furthermore, a statistically significant higher median values for both DDI-AE 1 and DDI-AE 2 score were found in patients with adverse DDI, reflecting the possible additive or synergistic risk of multiple DDIs, in causing adverse outcome. The LexiInteract monograph denotes interacting/noninteracting members of a specific pharmacological group, giving the opportunity to improve patient's therapy through avoiding potentially harmful DDIs. Furthermore, medical charts review presents significant workload for clinicians, to search for the evidence and occurrence of DDIs. ${ }^{40}$ That is one of the main reason why DDI-related outcomes are still underinvestigated and underreported. Nowadays, different data mining strategies are being developed in identifying ADRs and DDI-related ADRs, to get closer to their real burden. ${ }^{41,42}$ Validation of the DDI-AE probability score is certainly needed in a larger population, however, the idea of stratifying patients according to DDI-related risk might ease future research, as well as the clinical practice.

General recommendations for future research to improve DDI alerts have been given. One of them is a requirement to determine frequencies and clinical consequences of DDIs. ${ }^{43}$ In line with that, the main strength of the study is the identification of adverse DDIs that caused or contributed to hospital admission in patients with CVD. Detailed data at the admission and during the hospital stay were collected, which enabled comprehensive evaluation of adverse DDIs. On the other hand, our results are derived from 351 patient sample, which is the main limitation of the study. DDIs were underreported in this population, nevertheless, due to the number and nature of drugs used in CVD therapy, a higher risk might be expected. Lack of information in this area can easily result in over, as well as underestimation of the clinical consequences of DDIs. ${ }^{12}$ Apparently, our results regarding the estimated prevalence of adverse 
DDIs should be interpreted with caution due to small sample size. It has been recognized that the studies with a larger sample size showed low incidences and studies with a smaller size showed high incidences of adverse outcomes due to DDIs. Results from studies with a smaller sample size have a larger standard error, and outliers to higher numbers occur more often, wrongly presenting a higher incidence. Further, it is possible that in the smaller studies medication histories were studied in more detail than in the larger ones, and were therefore more readily able to recognise adverse patient outcomes due to DDIs. On the other hand, this may indicate that the percentages found in the larger studies are an underestimation of the true risk. ${ }^{12}$ It was also confirmed that a higher rates for adverse events have been found if active strategy was applied in data acquisition, compared to spontaneous reporting, which was the case in our research. ${ }^{44}$ Moreover, this is a single-center study exploring the outcomes of the patients admitted to the academic hospital ward. It is likely that the reported results might be unrepresentative for other settings, such as non-academic, non-speciality or outpatient setting. Therefore, the proposed tool for identification of high-risk patients needs to be tested and validated in other settings or in other populations. Further research is needed in the larger sample to obtain the generalizability of the findings, and to improve prospective risk measures to deal with DDI-related adverse therapy outcomes.

\section{Conclusions}

Our study revealed significant burden of DDIs-related ADRs in CVD admissions to the cardiology service of our hospital. Generally, about one in ten patients hospitalized with CVD might have a DDI contributing to the hospitalisation. Given the high prevalence of CVD, DDIrelated harm might be significant burden worldwide. Electronic databases can be easily applied in predicting and preventing DDIs, but further improvements have been advocated to increase the quality and acceptance rates of DDI alerts. Identification of patients with high cumulative DDI-adverse event risk might ease the recognition of DDI-related harm and improve the use of 
electronic databases in clinical practice.

\section{TRANSPARENCY}

Declaration of funding: We would like to acknowledge the Ministry of Education, Science and Technological Development, Belgrade, the Republic of Serbia for the financial support (Experimental and Clinical Pharmacological Investigations of Mechanisms of Drug Action and Interactions in Nervous and Cardiovascular System, [No. 175023]).

Declarations of interest: none. Peer reviewers on this manuscript have no relevant financial or other relationships to disclose.

Author contributions: All authors contributed to this work. Radovanović S. and Stevanović P. were responsible for study conception and acquisition of patient data. Kovačević M. entered and analysed the data, and was responsible for writing this paper. Vezmar Kovačević S. and Miljković B. contributed in interpreting and discussing the results, and writing the paper as well. All authors were responsible for revising this work critically for important intellectual content. All authors are accountable for all aspects of this work.

Acknowledgments: No assistance in the preparation of this article is to be declared. 


\section{References:}

1. Alshammari TM. Drug safety: The concept, inception and its importance in patients' health. Saudi Pharm J. 2016;24(4):405-412.

2. Dumbreck S, Flynn A, Nairn M, Wilson M, Treweek S, Mercer SW, et al. Drug-disease and drug-drug interactions: systematic examination of recommendations in $12 \mathrm{UK}$ national clinical guidelines. BMJ. 2015;350:h949.

3. Batel Marques F, Penedones A, Mendes D, Alves C. A systematic review of observational studies evaluating costs of adverse drug reactions. Clinicoecon Outcomes Res. 2016;8:413-426.

4. Shamliyan TA, Kane RL. Drug-Related Harms in Hospitalized Medicare Beneficiaries: Results From the Healthcare Cost and Utilization Project, 2000-2008. J Patient Saf. 2016;12(2):89-107.

5. World Health Organisation (WHO). Safety of medicine: a guide to detecting and reporting adverse drug reaction. Geneva: WHO; 2002.

6. Leone R, Magro L, Moretti U, Cutroneo P, Moschini M, Motola D, et al. Identifying adverse drug reactions associated with drug-drug interactions: data mining of a spontaneous reporting database in Italy. Drug Saf. 2010;33(8):667-675.

7. Dechanont S, Maphanta S, Butthum B, Kongkaew C. Hospital admissions/visits associated with drug-drug interactions: a systematic review and meta-analysis. Pharmacoepidemiol Drug Saf. 2014;23(5):489-497.

8. Benard-Laribiere A, Miremont-Salame G, Perault-Pochat MC, Noize P, Haramburu F, centres ESGobotFnop. Incidence of hospital admissions due to adverse drug reactions in France: the EMIR study. Fundam Clin Pharmacol. 2015;29(1):106-111.

9. Pirmohamed M, James S, Meakin S, Green C, Scott AK, Walley TJ, et al. Adverse drug reactions as cause of admission to hospital: prospective analysis of 18820 patients. BMJ. 2004;329(7456):15-19.

10. Pedros C, Formiga F, Corbella X, Arnau JM. Adverse drug reactions leading to urgent hospital admission in an elderly population: prevalence and main features. Eur J Clin Pharmacol. 2016;72(2):219-226.

11. Montane E, Arellano AL, Sanz Y, Roca J, Farre M. Drug-related deaths in hospital inpatients: A retrospective cohort study. Br J Clin Pharmacol. 2018;84(3):542-552.

12. Becker ML, Kallewaard M, Caspers PW, Visser LE, Leufkens HG, Stricker BH. Hospitalisations and emergency department visits due to drug-drug interactions: a literature review. Pharmacoepidemiol Drug Saf. 2007;16(6):641-651.

13. Hines LE, Murphy JE, Grizzle AJ, Malone DC. Critical issues associated with drug-drug interactions: highlights of a multistakeholder conference. Am J Health Syst Pharm. 2011;68(10):941-946.

14. Zheng WY, Richardson LC, Li L, Day RO, Westbrook JI, Baysari MT. Drug-drug interactions and their harmful effects in hospitalised patients: a systematic review and meta-analysis. Eur J Clin Pharmacol. 2018;74(1):15-27.

15. Bykov K, Gagne JJ. Generating Evidence of Clinical Outcomes of Drug-Drug Interactions. Drug Saf. 2017;40(2):101-103.

16. Romagnoli KM, Nelson SD, Hines L, Empey P, Boyce RD, Hochheiser H. Information needs for making clinical recommendations about potential drug-drug interactions: a synthesis of literature review and interviews. BMC Med Inform Decis Mak. 2017;17(1):21.

17. Al Hamid A, Ghaleb M, Aljadhey H, Aslanpour Z. A systematic review of hospitalization resulting from medicine-related problems in adult patients. Br J Clin Pharmacol. 2014;78(2):202-217. 
18. Letinier L, Cossin S, Mansiaux Y, Arnaud M, Salvo F, Bezin J, et al. Risk of Drug-Drug Interactions in Out-Hospital Drug Dispensings in France: Results From the DRUG-Drug Interaction Prevalence Study. Front Pharmacol. 2019;10:265.

19. Fettah H, Moutaouakkil Y, Sefrioui MR, Moukafih B, Bousliman Y, Bennana A, et al. Detection and analysis of drug-drug interactions among hospitalized cardiac patients in the Mohammed V Military Teaching Hospital in Morocco. Pan Afr Med J. 2018;29:225.

20. Murtaza G, Khan MY, Azhar S, Khan SA, Khan TM. Assessment of potential drug-drug interactions and its associated factors in the hospitalized cardiac patients. Saudi Pharm J. 2016;24(2):220-225.

21. Kovacevic M, Vezmar Kovacevic S, Miljkovic B, Radovanovic S, Stevanovic P. The prevalence and preventability of potentially relevant drug-drug interactions in patients admitted for cardiovascular diseases: A cross-sectional study. Int J Clin Pract. 2017;71(10):e13005.

22. Rahim SA, Mody A, Pickering J, Devereaux PJ, Yusuf S. Iatrogenic adverse events in the coronary care unit. Circ Cardiovasc Qual Outcomes. 2009;2(5):437-442.

23. Devi P, Kamath DY, Anthony N, Santosh S, Dias B. Patterns, predictors and preventability of adverse drug reactions in the coronary care unit of a tertiary care hospital. Eur J Clin Pharmacol. 2012;68(4):427-433.

24. Al Hamid A, Aslanpour Z, Aljadhey H, Ghaleb M. Hospitalisation Resulting from Medicine-Related Problems in Adult Patients with Cardiovascular Diseases and Diabetes in the United Kingdom and Saudi Arabia. Int J Environ Res Public Health. 2016;13(5).

25. Urbina O, Ferrandez O, Luque S, Grau S, Mojal S, Pellicer R, et al. Patient risk factors for developing a drug-related problem in a cardiology ward. Ther Clin Risk Manag. 2015;11:9-15.

26. Roblek T, Trobec K, Mrhar A, Lainscak M. Potential drug-drug interactions in hospitalized patients with chronic heart failure and chronic obstructive pulmonary disease. Arch Med Sci. 2014;10(5):920-932.

27. Horn JR, Hansten PD, Chan LN. Proposal for a new tool to evaluate drug interaction cases. Ann Pharmacother. 2007;41(4):674-680.

28. Ahn EK, Cho SY, Shin D, Jang C, Park RW. Differences of Reasons for Alert Overrides on Contraindicated Co-prescriptions by Admitting Department. Healthc Inform Res. 2014;20(4):280-287.

29. Lexicomp Online®, LexiInteract. Hudson, Ohio: Lexi-Comp, Inc.

30. Hosmer DW, Lemeshow S, Chapter 5: Assessing the Fit of the Model, in Applied Logistic Regression. John Wiley and Sons, (2000): New York, NY p. 160-164.

31. Moller S, Bernardi M. Interactions of the heart and the liver. Eur Heart J. 2013;34(36):2804-2811.

32. Faulx MD, Francis GS. Adverse drug reactions in patients with cardiovascular disease. Curr Probl Cardiol. 2008;33(12):703-768.

33. Mugoša S, Bukumirić Z, Kovačević A, Bošković A, Protić D, Todorović Z. Adverse drug reactions in hospitalized cardiac patients: characteristics and risk factors. Vojnosanitetski Pregled. 2015;72(11):975-981.

34. Mateti U, Rajakannan T, Nekkanti H, Rajesh V, Mallaysamy S, Ramachandran P. Drugdrug interactions in hospitalized cardiac patients. J Young Pharm. 2011;3(4):329-333.

35. Andersson ML, Bottiger Y, Kockum H, Eiermann B. High Prevalence of Drug-Drug Interactions in Primary Health Care is Caused by Prescriptions from other Healthcare Units. Basic Clin Pharmacol Toxicol. 2018;122(5):512-516.

36. Schreiber R, Gregoire JA, Shaha JE, Shaha SH. Think time: A novel approach to analysis of clinicians' behavior after reduction of drug-drug interaction alerts. Int J Med Inform. 2017;97:59-67. 
37. Bryant AD, Fletcher GS, Payne TH. Drug interaction alert override rates in the Meaningful Use era: no evidence of progress. Appl Clin Inform. 2014;5(3):802-813.

38. Page N, Baysari MT, Westbrook JI. A systematic review of the effectiveness of interruptive medication prescribing alerts in hospital CPOE systems to change prescriber behavior and improve patient safety. Int J Med Inform. 2017;105:22-30.

39. Payne TH, Hines LE, Chan RC, Hartman S, Kapusnik-Uner J, Russ AL, et al. Recommendations to improve the usability of drug-drug interaction clinical decision support alerts. J Am Med Inform Assoc. 2015;22(6):1243-1250.

40. Zhou S, Kang H, Yao B, Gong Y. An automated pipeline for analyzing medication event reports in clinical settings. BMC Med Inform Decis Mak. 2018;18(Suppl 5):113.

41. Ventola CL. Big Data and Pharmacovigilance: Data Mining for Adverse Drug Events and Interactions. P T. 2018;43(6):340-351.

42. Iyer SV, Harpaz R, LePendu P, Bauer-Mehren A, Shah NH. Mining clinical text for signals of adverse drug-drug interactions. J Am Med Inform Assoc. 2014;21(2):353-362.

43. Tilson H, Hines LE, McEvoy G, Weinstein DM, Hansten PD, Matuszewski K, et al. Recommendations for selecting drug-drug interactions for clinical decision support. Am J Health Syst Pharm. 2016;73(8):576-585.

44. Krahenbuhl-Melcher A, Schlienger R, Lampert M, Haschke M, Drewe J, Krahenbuhl S. Drug-related problems in hospitals: a review of the recent literature. Drug Saf. 2007;30(5):379-407. 
Table 1. Drug-drug interactions risk rating scale according to the LexiInteract database

\begin{tabular}{|c|c|c|}
\hline Risk Rating & Action & Description \\
\hline $\mathrm{A}$ & No Interaction & $\begin{array}{l}\text { Data have not demonstrated either pharmacodynamic or } \\
\text { pharmacokinetic interactions between the specified agents. }\end{array}$ \\
\hline B & No action needed & $\begin{array}{l}\text { Data demonstrate that the specified agents may interact } \\
\text { with each other, but there is little to no evidence of clinical } \\
\text { concern resulting from their concomitant use. }\end{array}$ \\
\hline $\mathrm{C}$ & Monitor therapy & $\begin{array}{l}\text { Data demonstrate that the specified agents may interact } \\
\text { with each other in a clinically significant manner. The } \\
\text { benefits of concomitant use usually outweigh the risks. An } \\
\text { appropriate monitoring plan should be implemented to } \\
\text { identify potential negative effects. Dosage adjustments of } \\
\text { one or both agents may be needed in a minority of patients. }\end{array}$ \\
\hline $\mathrm{D}$ & Modify regimen & $\begin{array}{l}\text { Data demonstrate that the two medications may interact } \\
\text { with each other in a clinically significant manner. A } \\
\text { patient-specific assessment must be conducted to } \\
\text { determine whether the benefits of concomitant therapy } \\
\text { outweigh the risks. Specific actions must be taken in order } \\
\text { to realize the benefits and/or minimize the toxicity - } \\
\text { aggressive monitoring, empiric dosage changes, choosing } \\
\text { alternative agents. }\end{array}$ \\
\hline $\mathrm{X}$ & Avoid combination & $\begin{array}{l}\text { Data demonstrate that the specified agents may interact } \\
\text { with each other in a clinically significant manner. The risks } \\
\text { associated with concomitant use of these agents usually } \\
\text { outweigh the benefits. These agents are generally } \\
\text { considered contraindicated. }\end{array}$ \\
\hline
\end{tabular}


Table 2. Demographic and clinical characteristics of the study population

\begin{tabular}{|c|c|c|c|}
\hline & \multicolumn{2}{|c|}{ ADR attributed to DDI } & \multirow[b]{2}{*}{ p value } \\
\hline & \multirow{2}{*}{$\begin{array}{l}\text { Yes }(\mathbf{N}=\mathbf{3 4}) \\
\text { number of patients }(\%)\end{array}$} & \multirow{2}{*}{$\begin{array}{l}\text { No }(\mathbf{N}=\mathbf{3 1 7}) \\
\text { number of patients }(\%)\end{array}$} & \\
\hline & & & \\
\hline Gender, female & $11(32.35)$ & $157(49.53)$ & 0.211 \\
\hline Age, years & & & \\
\hline mean \pm S.D., total range & $72.18 \pm 11.05,49-89$ & $69.80 \pm 9.98,29-88$ & 0.194 \\
\hline$\geq 65$ & $24(70.59)$ & $230(72.56)$ & 0.807 \\
\hline \multicolumn{4}{|l|}{ Number of drugs } \\
\hline median [IQR], total range & 8 [6-9.25], 5-15 & $6[4-7], 1-14$ & $<0.001$ \\
\hline$\geq 5$ & $34(100)$ & $208(65.62)$ & $<0.001$ \\
\hline$\geq 10$ & $8(23.53)$ & $23(7.26)$ & 0.005 \\
\hline \multicolumn{4}{|l|}{ Charlson comorbidity index } \\
\hline median [IQR], total range & $3[2-4.25], 0-6$ & $3[2-4], 0-8$ & 0.346 \\
\hline mean \pm S.D. & $3.21 \pm 1.59$ & $2.97 \pm 1.63$ & 0.425 \\
\hline \multicolumn{4}{|l|}{ Length of stay, days } \\
\hline mean \pm S.D., total range & $10.65 \pm 9.59,2-54$ & $9.40 \pm 5.73$ & 0.266 \\
\hline \multicolumn{4}{|l|}{ Clinical diagnosis } \\
\hline heart failure & $17(50)$ & $130(41.01)$ & 0.313 \\
\hline angina pectoris & $7(20.59)$ & $101(31.86)$ & 0.176 \\
\hline hypertension & $18(52.94)$ & $218(68.77)$ & 0.062 \\
\hline arrhythmia & $20(58.82)$ & $148(46.69)$ & 0.178 \\
\hline myocardial infarction in anamnesis & $3(8.82)$ & $39(12.30)$ & 0.552 \\
\hline cerebral infarction in anamnesis & $3(8.82)$ & $17(5.36)$ & 0.427 \\
\hline diabetes mellitus & $10(29.41)$ & $90(28.39)$ & 0.900 \\
\hline respiratory disease & $5(14.71)$ & 7.89) & 0.192 \\
\hline endocrine disease, excluding diabetes & $2(5.88)$ & $16(5.05)$ & 0.834 \\
\hline gastrointestinal disease & $3(8.82)$ & $18(5.68)$ & 0.442 \\
\hline renal disease & $1(2.94)$ & $24(7.57)$ & 0.492 \\
\hline liver disease & 0 & $10(3.15)$ & 0.607 \\
\hline \multicolumn{4}{|l|}{$\begin{array}{l}\text { Clinical parameters at admission } \\
\text { mean } \pm \text { S.D. }\end{array}$} \\
\hline heart rate & 7.7 & $88.9 \pm 23.9$ & 0.749 \\
\hline systolic blood pressure & $=19.07$ & $140.28 \pm 24.23$ & 0.057 \\
\hline diastolic blood pressure & & $84.43 \pm 13.79$ & 0.008 \\
\hline \multicolumn{4}{|l|}{ Reason for admission } \\
\hline heart failure & $18(52.94)$ & $127(40.06)$ & 0.160 \\
\hline arrhythmia & $7(20.59)$ & $56(17.67)$ & 0.692 \\
\hline hypertension & $1(2.94)$ & $45(14.20)$ & 0.065 \\
\hline angina pectoris & 0 & $40(12.62)$ & 0.021 \\
\hline
\end{tabular}

ADR - adverse drug reaction; DDI - drug-drug interaction; S.D. - standard deviation; IQR -

interquartile range; risk rating C - Monitor therapy; risk rating D - Consider therapy

modification; risk rating $X$ - Avoid combination 
Table 3. Drug classes implicated in adverse drug-drug interactions

Drug class

Cardiovascular system

Frequency $(\%)$

ACE inhibitors

46 (41.07)

Aldosterone antagonists

$10(8.93)$

Antiarrhythmics, class III

$8(7.14)$

Digitalis glycosides

$6(5.36)$

Antiarrhythmics, class Ic

$5(4.46)$

Alpha and beta blocking agents

$3(2.68)$

HMG CoA reductase inhibitors

$3(2.68)$

High-ceiling diuretics, sulfonamides

$3(2.68)$

Peripheral vasodilatators, purine derivatives

$2(1.79)$

$2(1.79)$

Calcium channel blockers, dihydropyridine derivatives

$2(1.79)$

Organic nitrates

$1(0.89)$

Beta blocking agents, selective

$1(0.89)$

Respiratory system

27 (24.11)

Selective beta-2-adrenoreceptor agonists

15 (13.39)

Xanthines

Anticholinergics, inhalations

Blood and blood forming organs

Platelet aggregation inhibitors excl. Heparin

$8(7.14)$

$4(3.57)$

Vitamin K antagonists

$17(15.18)$

$9(8.04)$

$8(7.14)$

\section{Nervous system}

14 (12.50)

Barbiturates and derivatives

$3(2.68)$

Antipsychotics

$3(2.68)$

Analgesics and antipyretics, pyrazolones

$2(1.79)$

Benzodiazepine derivatives

$2(1.79)$

$1(0.89)$

$1(0.89)$

$1(0.89)$

$1(0.89)$

4 (3.57)

$4(3.57)$

3 (2.68)

$3(2.68)$

1 (0.89)

$1(0.89)$

antagonists

$112(100 \%)$ 
Table 4. Adverse drug reactions attributed to drug-drug interactions identified at the hospital admission

\section{Adverse drug reactions} DDIs
Patient management
Mechanism

Risk Rating, Severity, Reliability

\begin{tabular}{|c|c|c|c|c|}
\hline $\begin{array}{l}\text { Heart rate / rhythm (23) } \\
\text { tachycardia, irregular heart } \\
\text { rhythm }\end{array}$ & & & & \\
\hline $\begin{array}{l}\text { aminophylline }+ \\
\text { amiodarone }\end{array}$ & $\begin{array}{l}\text { monitor for toxic effects of } \\
\text { theophylline derivatives }\end{array}$ & PK (metabolism) & $\begin{array}{l}\text { C, Moderate, } \\
\text { Fair }\end{array}$ & 1 \\
\hline $\begin{array}{l}\text { aminophylline }+ \\
\text { propafenone }\end{array}$ & & $\begin{array}{l}\text { PK (metabolism } \\
\text { CYP1A2) }\end{array}$ & $\begin{array}{l}\text { C, Moderate, } \\
\text { Fair }\end{array}$ & 1 \\
\hline $\begin{array}{l}\text { aminophylline }+ \\
\text { fenoterol }\end{array}$ & $\begin{array}{l}\text { monitor for increased effects } \\
\text { of sympathomimetics (eg, }\end{array}$ & PD & $\begin{array}{l}\text { C, Moderate, } \\
\text { Fair }\end{array}$ & 4 \\
\hline $\begin{array}{l}\text { aminophylline + } \\
\text { salbutamol }\end{array}$ & blood pressure, heart rate) & PD & $\begin{array}{l}\text { C, Moderate, } \\
\text { Fair }\end{array}$ & \\
\hline $\begin{array}{l}\text { aminophylline + } \\
\text { salmeterol }\end{array}$ & & PD & $\begin{array}{l}\text { C, Moderate, } \\
\text { Fair }\end{array}$ & \\
\hline $\begin{array}{l}\text { clarithromycin + } \\
\text { digoxin }\end{array}$ & $\begin{array}{l}\text { monitor for increased serum } \\
\text { concentrations and toxic } \\
\text { effects of cardiac glycosides }\end{array}$ & $\begin{array}{l}\text { PK (P-gp, } \\
\text { metabolism } \\
\text { CYP3A) / PD }\end{array}$ & $\begin{array}{l}\text { C, Moderate, } \\
\text { Excellent }\end{array}$ & 1 \\
\hline digoxin + erythromycin & & $\begin{array}{l}\text { PK (P-gp, } \\
\text { metabolism } \\
\text { CYP3A) / PD }\end{array}$ & $\begin{array}{l}\text { C, Moderate, } \\
\text { Excellent }\end{array}$ & 1 \\
\hline $\begin{array}{l}\text { erythromycin + } \\
\text { salmeterol }\end{array}$ & $\begin{array}{l}\text { monitor closely for adverse } \\
\text { cardiovascular effects of } \\
\text { salmeterol (e.g., increased } \\
\text { heart rate, prolonged QT } \\
\text { interval) }\end{array}$ & $\begin{array}{l}\text { PK (metabolisı } \\
\text { CYP3A4) }\end{array}$ & $\begin{array}{l}\text { C, Moderate, } \\
\text { Fair }\end{array}$ & 1 \\
\hline $\begin{array}{l}\text { erythromycin }+ \\
\text { propafenone }\end{array}$ & $\begin{array}{l}\text { monitor for QTc interval } \\
\text { prolongation and ventricular } \\
\text { arrhythmias. Patients with } \\
\text { other risk factors (eg, older } \\
\text { age, female sex, bradycardia, } \\
\text { hypokalemia, } \\
\text { hypomagnesemia, heart } \\
\text { disease, and higher drug } \\
\text { concentrations) are at greater } \\
\text { risk }\end{array}$ & $\begin{array}{l}\text { PK (P-gp, } \\
\text { metabolism } \\
\text { CYP3A4) / PD }\end{array}$ & $\begin{array}{l}\text { C, Moderate, } \\
\text { Fair }\end{array}$ & 1 \\
\hline fenoterol + salbutamol & $\begin{array}{l}\text { monitor for increased effects } \\
\text { of sympathomimetics (eg, }\end{array}$ & PD & $\begin{array}{l}\text { C, Moderate, } \\
\text { Fair }\end{array}$ & 1 \\
\hline fenoterol + salmeterol & blood pressure, heart rate) & PD & $\begin{array}{l}\text { C, Moderate, } \\
\text { Fair }\end{array}$ & 2 \\
\hline $\begin{array}{l}\text { fluphenazine }+ \\
\text { chlorpromazine }\end{array}$ & $\begin{array}{l}\text { monitor for additive } \\
\text { anticholinergic effects; } \\
\text { monitor for additive CNS- } \\
\text { depressant effects }\end{array}$ & PD & $\begin{array}{l}\text { C, Moderate, } \\
\text { Good }\end{array}$ & 1 \\
\hline $\begin{array}{l}\text { ipratropium + } \\
\text { tiotropium }\end{array}$ & $\begin{array}{l}\text { avoid concurrent use of } \\
\text { ipratropium with any other } \\
\text { drugs that have } \\
\text { anticholinergic properties. If } \\
\text { such combinations can not be } \\
\text { avoided, monitor patients } \\
\text { closely for evidence of } \\
\text { anticholinergic-related } \\
\text { toxicities (e.g., urinary } \\
\text { retention, constipation, } \\
\text { tachycardia, dry mouth) }\end{array}$ & $\mathrm{PD}$ & X, Major, Fair & 2 \\
\hline
\end{tabular}







NSAID therapy (fluid accumulation/edema).

Monitor for decreased

therapeutic effects of ACE

inhibitor

hypotension
benserazide/levodopa +
furosemide

increased risk for

PD

C, Moderate,

symptomatic postural

Fair

hypotension. Advise patients

to minimize the risk of

dizziness or falls

bromazepam +

monitor for additive CNS-

depressant effects. Such

PD

C, Moderate, 1

clonazepam

effects may include, but are

not limited to, ataxia,

confusion, drowsiness,

respiratory depression, and

weakness

carvediol + fluoxetine

consider an alternative to

avoid toxicity of the

PK (metabolism

D, Moderate,

carvedilol. Some

combinations are specifically

contraindicated by

manufacturers. Please review

applicable package inserts

enalapril +

monitor blood pressure

closely and advise patients of

the possibility for enhanced

blood pressure lowering

ntoxifylline

metoprolol + tamsulosin

monitor closely for additive

hypotensive effects

\section{Hyperkalemia (6) \\ enalapril + \\ spironolactone \\ fosinopril + \\ spironolactone \\ metamizole + \\ spironolactone}

\section{Low red blood cells count}

(3)

\section{allopurinol + captopri \\ allopurinol + fosinopril \\ allopurinol + lisinopril \\ Elevated liver enzymes (AST and ALT) (2)}

monitor for increased

incidence of hyperkalemia

monitor blood pressure and

potassium concentrations

closely
CYP2D6)

Fair

PD C, Moderate, 1

C, Moderate, 1

Fair

C, Moderate,
PD
C, Major, Good 2
PD
C, Major, Good 3
PD
C, Major, Fair $\quad 1$

1

\begin{tabular}{|c|c|c|c|c|}
\hline $\begin{array}{l}\text { amiodarone }+ \\
\text { simvastatin }\end{array}$ & $\begin{array}{l}\text { consider using pravastatin; } \\
\text { limit the simvastatin dose to } \\
20 \mathrm{mg} \text { daily and monitor for } \\
\text { evidence of simvastatin } \\
\text { toxicities (eg, myalgia, liver } \\
\text { function test elevations, } \\
\text { rhabdomyolysis) }\end{array}$ & $\begin{array}{l}\text { PK (metabolism } \\
\text { CYP3A4) }\end{array}$ & D, Major, Good & 2 \\
\hline \multicolumn{5}{|l|}{ Epigastric pain (1) } \\
\hline digoxin+spironolactone & $\begin{array}{l}\text { monitor closely for signs or } \\
\text { symptoms of digoxin toxicity. } \\
\text { Additional monitoring of } \\
\text { digoxin concentrations may } \\
\text { also be warranted, but }\end{array}$ & PK (unknown) & $\begin{array}{l}\text { C, Moderate, } \\
\text { Fair }\end{array}$ & 1 \\
\hline
\end{tabular}

$\begin{array}{llll}\text { if allopurinol must be used in } & \text { unknown } & \text { D, Major, Fair } & 1 \\ \text { an ACE inhibitor patient, } & \text { unknown } & \text { D, Major, Fair } & 1 \\ \text { monitor for evidence of } & \text { unknown } & \text { D, Major, Fair } & 1 \\ \text { hypersensitivity reactions } & & & \end{array}$




\begin{tabular}{clll}
\hline & $\begin{array}{l}\text { spironolactone and its } \\
\text { metabolites may interfere } \\
\text { with many different } \\
\text { commerical digoxin assays }\end{array}$ & & \\
\hline clozapine + venlafaxine & $\begin{array}{l}\text { monitor patients extra closely } \\
\text { for evidence of serotonin } \\
\text { toxicity (e.g., mental status } \\
\text { changes, autonomic }\end{array}$ & C, Moderate, \\
& instability, and neuromuscular \\
& hyperactivity) or neuroleptic \\
& malignant syndrome (e.g., \\
& hyperthermia, muscle rigidity, \\
& autonomic dysfunction) & \\
&
\end{tabular}

PK - pharmacokinetic; PD - pharmacodynamic; risk rating C - Monitor therapy; risk rating D -

Consider therapy modification; risk rating X - Avoid combination; AST - aspartate

aminotransferase; ALT - alanine aminotransferase 
Table 5. Factors associated with adverse drug-drug interactions

\begin{tabular}{|c|c|c|c|c|}
\hline Patients characteristics & $\begin{array}{l}\text { crude OR } \\
(95 \% \text { CI })\end{array}$ & p value & $\begin{array}{l}\text { a adjusted OR } \\
(95 \% \mathrm{CI})\end{array}$ & p value \\
\hline Gender, male & $1.59(0.77-3.27)$ & 0.214 & $1.21(0.56-2.61)$ & 0.634 \\
\hline Age $\geq 65$ years & $0.91(0.42-1.97)$ & 0.807 & $0.57(0.24-1.34)$ & 0.195 \\
\hline Number of drugs & $1.42(1.23-1.63)$ & $<0.001$ & - & \\
\hline Charlson comorbidity index & $1.09(0.88-1.35)$ & 0.424 & $0.76(0.58-1.00)$ & 0.052 \\
\hline \multicolumn{5}{|l|}{ Clinical diagnosis } \\
\hline Heart failure & $1.44(0.71-2.92)$ & 0.315 & $0.84(0.39-1.82)$ & 0.653 \\
\hline Angina pectoris & $0.55(0.23-1.32)$ & 0.181 & $0.36(0.14-0.91)$ & 0.030 \\
\hline Diabetes mellitus & $1.05(0.48-2.29)$ & 0.900 & $0.63(0.27-1.47)$ & 0.284 \\
\hline Hypertension & $0.51(0.25-1.04)$ & 0.065 & $0.46(0.21-0.99)$ & 0.047 \\
\hline Arrhythmia & $1.63(0.80-3.34)$ & 0.181 & $1.63(0.76-3.49)$ & 0.205 \\
\hline Respiratory disease & $2.01(0.72-5.66)$ & 0.184 & $1.02(0.32-3.28)$ & 0.978 \\
\hline \multicolumn{5}{|l|}{ Reason for admission } \\
\hline Heart failure & $1.66(0.81-3.37)$ & 0.164 & $1.00(0.46-2.18)$ & 0.993 \\
\hline Arrhythmia & $1.19(0.49-2.88)$ & 0.692 & $2.10(0.81-5.46)$ & 0.128 \\
\hline Hypertension & $0.18(0.02-1.36)$ & 0.096 & $0.30(0.04-2.28)$ & 0.243 \\
\hline \multicolumn{5}{|l|}{$\begin{array}{l}\text { Potential DDIs characteristics } \\
\text { risk rating }\end{array}$} \\
\hline$X$ & $7.57(1.62-35.39)$ & 0.010 & $2.35(0.41-13.43)$ & 0.338 \\
\hline $\mathrm{D}$ & $6.13(2.89-12.98)$ & $<0.001$ & $2.92(1.24-6.89)$ & 0.015 \\
\hline $\mathrm{C}$ & - & & & \\
\hline number of $\mathrm{C}>2$ & $9.17(2.75-30.59)$ & & $3.43(0.90-13.15)$ & 0.072 \\
\hline \multicolumn{5}{|l|}{ severity } \\
\hline major & $3.92(1.86-8.29)$ & 001 & $2.69(1.20-6.02)$ & 0.017 \\
\hline moderate & $2.14(1.04-4.39)$ & 0.038 & $1.32(0.62-2.83)$ & 0.476 \\
\hline \multicolumn{5}{|l|}{ reliability } \\
\hline excellent & $1.98(0.64-6.17)$ & 0.239 & $1.31(0.40-4.31)$ & 0.656 \\
\hline good & $1.79(0.83-3.84)$ & 0.139 & $1.19(0.53-2.71)$ & 0.673 \\
\hline fair & $3.46(1.68-7.11)$ & 0.001 & $2.82(1.28-6.23)$ & 0.010 \\
\hline \multicolumn{5}{|l|}{ mechanism } \\
\hline $\mathrm{PK} / \mathrm{PD}$ & $4.66(2.24-9.69)$ & $<0.001$ & $3.37(1.13-10.06)$ & 0.030 \\
\hline PK & $4.03(1.46-11.12)$ & 0.007 & $2.43(1.10-5.40)$ & 0.028 \\
\hline PD & $3.36(1.62-6.97)$ & 0.001 & $2.34(1.09-5.04)$ & 0.030 \\
\hline present additional risk factor & $0.67(0.08-5.68)$ & 0.711 & $1.02(0.09-11.12)$ & 0.987 \\
\hline \multicolumn{5}{|c|}{ OR - odds ratio; CI - confidence interval; a - odds ratio adjusted for number of drugs; risk } \\
\hline
\end{tabular}


Table 6. Calculation of DDI-AE probability score based on LexiInteract monograph items

\begin{tabular}{lcc} 
& \multicolumn{2}{c}{ DDI-AE probability scores } \\
\cline { 2 - 3 } Item & $\begin{array}{c}\text { DDI-AE } \\
\text { Points }\end{array}$ & $\begin{array}{c}\text { DDI-AE 2 } \\
\text { Points }\end{array}$ \\
\hline Presence of X class pDDI & 2 & 2 \\
Presence of D class pDDI & 3 & 3 \\
Presence of more than 2 C class pDDIs & 3 & 3 \\
Severity major & 3 & 3 \\
Severity moderate & 1 & 1 \\
Mechanism PK/PD & 3 & 3 \\
Mechanism PK & 2 & 2 \\
Mechanism PD & 2 & 2 \\
Number of drugs & - & multiplied by 1.4 \\
\hline pDDI - potential drug-drug interaction; risk rating C - Monitor therapy; risk rating D - Consider \\
therapy modification; risk rating X - Avoid combination; PK - pharmacokinetic; PD - \\
pharmacodynamic; PK/PD - pharmacokinetic/pharmacodynamics
\end{tabular}

Table 7. Predictive value of DDI-AE probability score

DDI-AE probability scores

ADR caused by DDI

DDI-AE 1

DDI-AE 2

(clinical panel + DIPS by Horn et

al.)

ROC analysis

AUC $(95 \%$ CI)

$\mathrm{p}$ value

$0.800(0.744-0.856)$

$<0.001$

$0.811(0.750-0.872)$

$<0.001$

\begin{tabular}{lcccc} 
& \multicolumn{2}{c}{ cut-off value } & \multicolumn{2}{c}{ cut-off value } \\
& $\mathbf{2}$ points & $\mathbf{2} \mathbf{8}$ points & $\mathbf{2 1 6}$ points & $\mathbf{2 0}$ points \\
Sensitivity & $\mathbf{7 6 . 5 \%}$ & $64.7 \%$ & $73.5 \%$ & $61.8 \%$ \\
Specificity & $77.9 \%$ & $80.4 \%$ & $66.9 \%$ & $83.6 \%$ \\
\hline
\end{tabular}

DIPS - Drug Interaction Probability Scale; CI - confidence interval 